\title{
RECIDIVAS REGIONAIS NOS PACIENTES COM CARCINOMA EPIDERMÓIDE DAS VIAS AERODIGESTIVAS SUPERIORES SUBMETIDOS À ESVAZIAMENTO CERVICAL
}

\author{
REGIONAL RECURRENCE POST NECK DISSECTION IN PATIENTS WITH \\ SQUAMOUS CELL CARCINOMA OF AERODIGESTIVE TRACT
}

\begin{abstract}
Ali Amar ${ }^{1}$
Abrão Rapoport, TCBC-SP ${ }^{1}$

RESUMO: Objetivo: Avaliar a localização das recidivas regionais em pacientes com carcinoma epidermóide de vias aerodigestivas superiores tratados com esvaziamento cervical, bem como os resultados do tratamento de resgate. Método: Foram avaliados os prontuários de 943 pacientes submetidos a esvaziamento cervical, dos quais foram selecionados 95 com diagnóstico de recidiva regional isolada como primeira manifestação de recorrência da doença. Foi avaliada a localização da recidiva (lado e nível linfático) e o controle da doença após o tratamento de resgate. Resultados: As recidivas ipsilaterais ocorreram no nível II em 57\% dos pacientes. $\mathrm{O}$ tratamento de resgate foi realizado em $51 \%$ das recidivas ipsilaterais e em $75 \%$ das recidivas contralaterais. O controle da doença 12 meses após o resgate foi de $31 \%$, sendo $25 \%$ nas recidivas ipsilaterais e $37 \%$ nas contralaterais. Conclusões: As recidivas cervicais ocorrem predominantemente no nível II. As recidivas no nível I são freqüentes apenas nos tumores de boca e as recidivas no nível V são raras. A recidiva cervical tem prognóstico reservado mesmo entre os pacientes submetidos à retratamento com intenção curativa.
\end{abstract}

Descritores: Carcinoma de células escamosas; Metástase neoplásica; Linfonodos; Esvaziamento cervical.

\section{INTRODUÇÃO}

Embora o esvaziamento cervical seja eficaz no controle da doença regional, a presença de metástases linfáticas está associada a decréscimo significativo nas taxas de sobrevida, visto que a doença metastática cervical também se associa à maior incidência de recidivas locais e à distância. A recidiva da doença, por sua vez, apresenta um prognóstico ainda mais reservado, com sobrevida a longo prazo inferior a $5 \%{ }^{1,2,3,4}$. A radioterapia pós-operatória tem sido preconizada com o intuito de diminuir a incidência de recidivas regionais, especialmente na presença de múltiplos linfonodos comprometidos e ruptura capsular macroscópica. A indicação do tratamento complementar, além da probabilidade de doença residual, considera a dificuldade em realizar o resgate cirúrgico de uma recidiva na área operada, partindo do pressuposto de que é mais adequado tratar a doença microscópica do que uma recidiva extensa.

1. Cirurgião do Departamento de Cirurgia de Cabeça e Pescoço e Otorrinolaringologia do Hospital Heliópolis, HOSPHEL, São Paulo.

Recebido em: 13/03/2002

Aceito para publicação em:13/08/2002

Trabalho realizado no Departamento de Cirurgia de Cabeça e Pescoço e Otorrinolaringologia do Hospital Heliópolis, HOSPHEL, São Paulo. 
Os resultados insatisfatórios do tratamento de resgate, refletindo tumores de comportamento agressivo, abrem espaço para o desenvolvimento de novas modalidades terapêuticas.

Este estudo tem por objetivo avaliar a localização das recidivas regionais nos pacientes portadores de carcinoma epidermóide das vias aerodigestivas superiores, assim como os resultados do tratamento de resgate.

\section{MÉTODO}

Foram avaliados os prontuários de 943 pacientes com carcinoma epidermóide de boca, faringe e laringe, tratados no Serviço de Cirurgia de Cabeça e Pescoço do Hospital Heliópolis entre 1977 e 1996. Todos os pacientes foram submetidos a tratamento cirúrgico do tumor primário e esvaziamento cervical, com ou sem radioterapia complementar.

Ocorreram 54 óbitos no primeiro mês pósoperatório, que foram excluídos da análise. Nos 889 remanescentes, a recidiva cervical foi diagnosticada em 124 pacientes, dos quais foram excluídos 29 pacientes com recidiva local ou segundo tumor prévio ou concomitante à recidiva regional, restando 95 pacientes com recidiva cervical como primeira manifestação da recidiva. Não foram incluídos os pacientes com recidiva peritraquestoma.

Entre os 95 pacientes, 87 eram masculinos e oito femininos. Em relação ao sítio primário, 32 apresentavam carcinoma de cavidade oral, 11 de orofaringe, 31 de hipofaringe e 21 de laringe. O tipo de esvaziamento realizado foi radical unilateral em 70 pacientes, radical bilateral em 20, seletivo unilateral em quatro, radical unilateral e seletivo contralateral em um paciente. $\mathrm{O}$ exame anátomopatológico destes espécimes foi pN0 em 27 e pN+ em 68 pacientes.

Foi avaliada a localização das recidivas, considerando cinco níveis linfáticos, a lateralidade e o sítio primário. O nível linfático I corresponde aos linfonodos submento-submandibulares; os níveis II, III e IV correspondem respectivamente aos linfonodos júgulo-carotídeos altos, médios e baixos; o nível V corresponde aos linfonodos cervicais posteriores, incluindo a fossa supraclavicular. As recidivas bilaterais foram consideradas entre as ipsilaterais como também entre as contralaterais. As recidivas em pacientes submetidos a esvaziamento bilateral

foram incluídas entre as ipsilaterais. O envolvimento dos diferentes níveis linfáticos foi expresso em número de pacientes com comprometimento do referido nível, considerando as recidivas em múltiplos níveis.

Foi avaliado o tratamento de resgate apenas nas recidivas unilaterais, levando em conta o tratamento prévio (com ou sem radioterapia) e o lado da recidiva. O controle da doença no pescoço foi avaliado pelo método de sobrevida atuarial de KaplanMeier. O sucesso do tratamento foi definido como controle da doença (loco-regional e à distância) por período igual ou superior a 12 meses após o resgate.

\section{RESULTADOS}

Quanto ao local da recidiva, 49 pacientes apresentaram recidivas no lado esvaziado, 36 no pescoço contralateral não esvaziado e cinco recidivaram em ambos os lados; em cinco pacientes não foi determinado o lado da recidiva. Em dois pacientes não foi registrado o nível linfático da recidiva. A lateralidade e o nível das recidivas está representado na Tabela-1. Três pacientes submetidos a esvaziamento radical apresentaram recidivas ipsilaterais fora da área de esvaziamento, sendo que um paciente apresentou recidiva na região parotídea, um na região retrofaríngea e um na região occipital. Um paciente submetido a esvaziamento supra-omo-hioideo apresentou recidiva no nível IV. As demais recidivas ipsilaterais, mesmo nos casos de esvaziamento seletivo, ocorreram no campo esvaziado.

As recidivas ipsilaterais ocorreram em 16 casos de carcinoma de cavidade oral, oito de orofaringe, 20 de hipofaringe e 10 de laringe. A localização destas recidivas está representada na Tabela-2.

Tabela 1 - Lateralidade e nível das recidivas em 86 pacientes*.

\begin{tabular}{lcc}
\hline Recidiva & Ipsilateral & Contralateral \\
\hline Nível I & 6 & 4 \\
Nível II & 31 & 20 \\
Nível III & 7 & 12 \\
Nível IV & 6 & 2 \\
Nível V & 5 & 3 \\
\hline * 5 pacientes com recidiva bilateral e 5 pacientes com recidivas \\
em dois níveis
\end{tabular}


Tabela 2 - Localização das recidivas ipsilaterais conforme o sítio primário.

\begin{tabular}{lcccc}
\hline & Cavidade Oral & Orofaringe $^{*}$ & Hipofaringe & Laringe \\
\hline Nível I & 4 & 1 & 1 & 0 \\
Nível II & 7 & 5 & 11 & 8 \\
Nível III & 2 & 1 & 4 & 0 \\
Nível IV & 2 & 1 & 3 & 0 \\
Nível V & 1 & 1 & 1 & 2 \\
\hline
\end{tabular}

* 1 paciente com recidiva em dois níveis

As recidivas ipsilaterais no nível II ocorreram em $57 \%$ dos pacientes, correspondendo a $61 \%(8 / 13)$ das recidivas em pacientes pN0 e em 56\% (23/41) das recidivas em pacientes $\mathrm{pN}+$.

Em relação à radioterapia pós-operatória, as recidivas ipsilaterais em $67 \%$ (21/31) dos pacientes não irradiados e em $43 \%$ (10/23) dos pacientes irradiados ocorreram no nível II.

Entre os pacientes com recidiva unilateral, o resgate foi realizado em 52 pacientes (61\%), sendo com cirurgia e radioterapia em 34 e radioterapia exclusiva em 18 . O resgate foi realizado em $51 \%$ das recidivas ipsilaterais e em $75 \%$ das recidivas contralaterais (Figura-1). Em 33 pacientes o tratamento foi paliativo, com quimioterapia ou medidas de suporte. Ocorreram três óbitos pós-operatórios relacionados a complicações do procedimento de resgate. Entre os pacientes resgatados, quatro estavam assintomáticos na ocasião da última consulta e foram perdidos de seguimento antes de 12 meses póstratamento.

O controle da doença após 12 meses foi de $17 \%$, sendo $12 \%$ para as recidivas ipsilaterais e $25 \%$ para as recidivas contralaterais. Considerando apenas

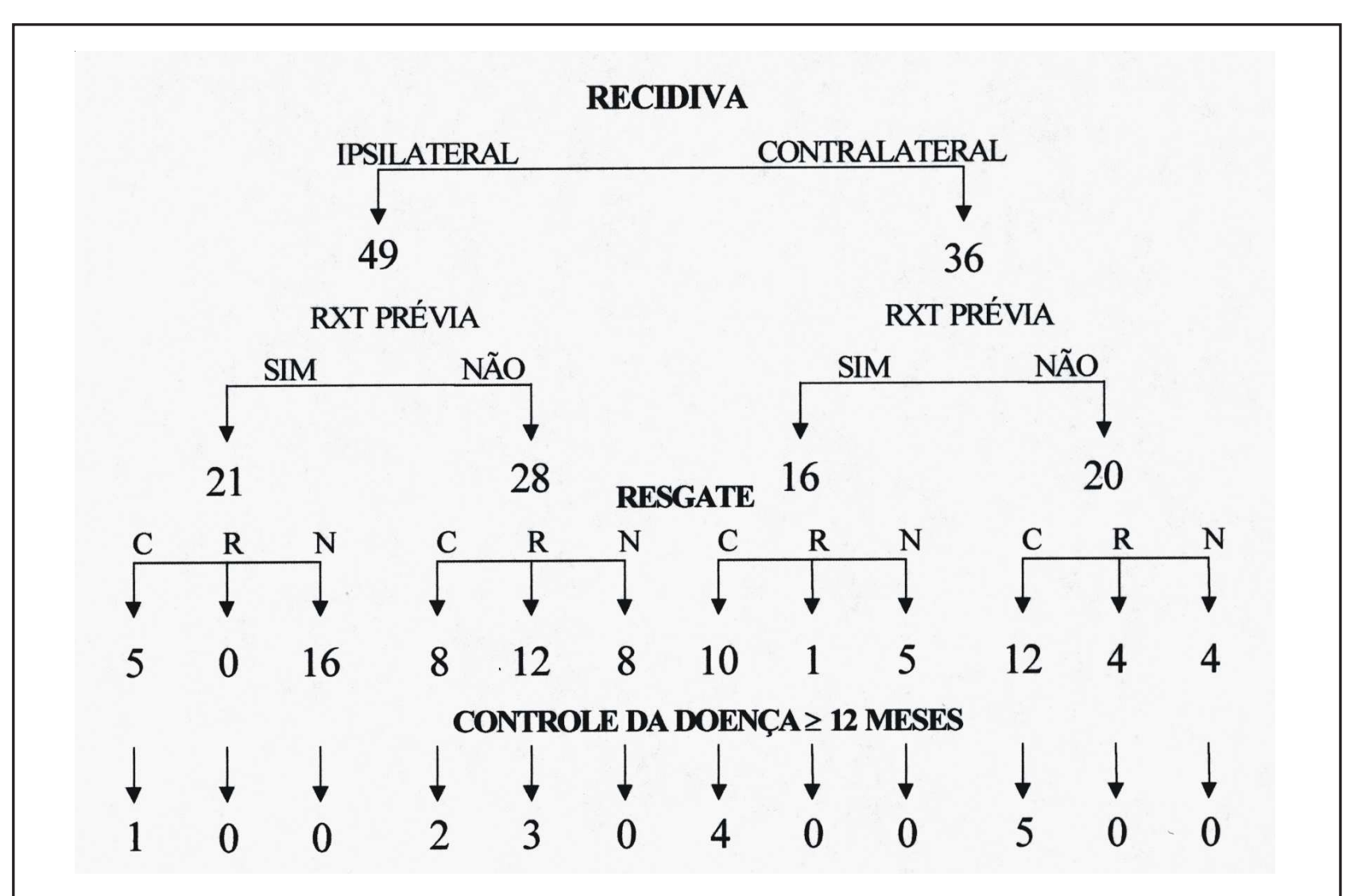

Figura 1 - Recidivas regionais unilaterais e tratamento de resgate. $R X T=$ radioterapia; $C=$ cirurgia / cirurgia + radioterapi; $R=$ radioterapia exclusiva $;=$ não resgatado. 


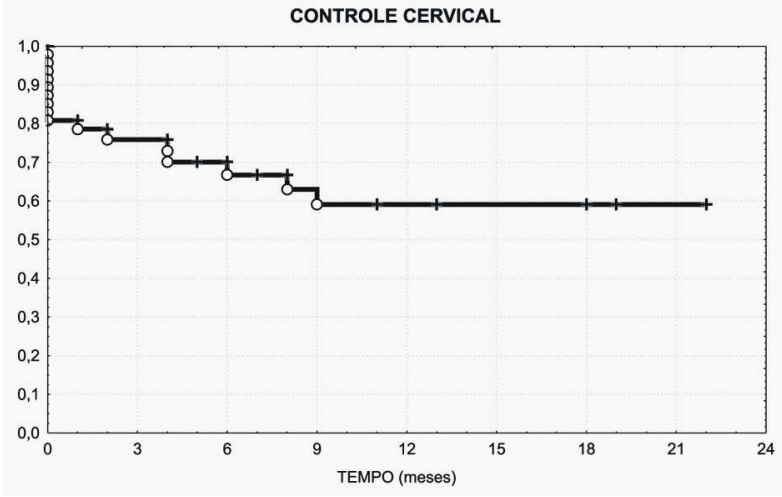

Figura 2 - Controle cervical em 47 pacientes com recidiva cervical unilateral submetidos a retratamento

os pacientes tratados e excluindo os perdidos de seguimento, estes valores sobem para $31 \%, 25 \%$ e $37 \%$ respectivamente.

O controle cervical após 12 meses foi de 59\% para os pacientes com recidiva cervical unilateral submetidos a tratamento de resgate, sendo $43 \%$ nas recidivas ipsilaterais e $65 \%$ nas recidivas contralaterais. Todas as recidivas cervicais foram diagnosticadas no primeiro ano após o retratamento. Os dados correspondem a análise de 47 pacientes que continham esta informação em seus prontuários (Figura-2).

As metástases à distância foram diagnosticadas em 13 pacientes com recidiva regional, em 8 destes pacientes após a realização do resgate. Após o tratamento da recidiva regional, 9 pacientes apresentaram recidiva local entre o $2^{\circ}$ e o $10^{\circ}$ mês e 2 pacientes desenvolveram segundo tumor.

\section{DISCUSSÃO}

A localização das recidivas cervicais é semelhante à distribuição habitual das metástases, acometendo preferencialmente o nível II. As recidivas no nível I são freqüentes apenas nos tumores de boca e as recidivas no nível V são raras. As recidivas nos esvaziamentos seletivos freqüentemente ocorrem dentro do campo operado, enfatizando o valor terapêutico deste tipo de esvaziamento ${ }^{5}$, assim como as recidivas após radioterapia exclusiva costumam ocorrer nos níveis linfáticos previamente comprometidos, a despeito da aplicação de doses mais altas nestas áreas ${ }^{6}$. O nível II é o local predominante das recidivas tanto entre os pacientes $\mathrm{pN} 0$ como $\mathrm{pN}+$, assim, além de uma possível doença residual nos casos que apresentam ruptura capsular, a permanência de remanescentes linfáticos deve ser considerada. Adicionalmente ao efeito de barreira da primeira estação de drenagem, os linfonodos próximos do tumor talvez apresentem condições adequadas para o desenvolvimento das metástases ${ }^{7}$. A maior proporção de recidivas no nível II entre os pacientes não irradiados sugere que a radioterapia complementar seja mais efetiva quando a doença apresenta o padrão habitual de disseminação.

Uma recidiva no nível II em um pescoço previamente esvaziado geralmente não é passível de resgate cirúrgico. Se previamente irradiado, a radioterapia externa não poderá ser empregada em doses efetivas, determinando um prognóstico reservado aos pacientes com recidiva cervical após tratamento combinado. As recidivas contralaterais reabrem a discussão quanto à realização de esvaziamento eletivo ou terapêutico. Algumas vezes, as metástases cervicais apresentam crescimento explosivo após a remoção do tumor primário, o que impõe a prática do esvaziamento eletivo quando o seguimento do paciente é incerto. As recidivas em áreas não tratadas apresentam maior facilidade de diagnóstico e tratamento, contrabalançando o pior prognóstico relacionado à doença metastática contralateral $^{8}$.

A exclusão dos pacientes com recidiva local prévia ou concomitante se fez apenas para caracterizar um grupo de pacientes quanto à apresentação clínica. Clinicamente é impossível distinguir se uma recidiva cervical é uma recidiva da metástase ou a metástase de uma recidiva (sítio primário). Têm sido observado em estudos experimentais que a doença ativa pode contribuir para a quiescência de focos metastáticos, assim como o tratamento de uma metástase pode favorecer o crescimento de outras metástases subclínicas, ambos mediados pela modulação da angiogênese ${ }^{9,10,11}$.

A incidência de metástases à distância provavelmente foi subestimada entre os pacientes com recidiva inoperável, não submetidos a exames complementares; o exame clínico e os métodos convencionais de imagem são limitados na detecção de doença residual no sítio primário. As recidivas no sítio primário e à distância são responsáveis por um número significativo de falhas no tratamento de resgate do pescoço, porém não pode ser desconsiderada a possibilidade de doença subclínica no pescoço em muitos destes casos que foram a óbito e não tiveram tempo suficiente para manifestar a doença regional. 
A terapia localizada é insuficiente na maioria destes pacientes e o sucesso do resgate pode estar relacionado a uma falha técnica no tratamento inicial. Apesar das baixas taxas de controle da doença, as taxas de controle no pescoço justificam o tratamento. Uma vez que a recidiva atesta a ineficácia do tratamento prévio, não se justificam medidas heróicas com as mesmas armas terapêuticas, nesta situação os aspectos relacionados à qualidade de vida adquirem maior importância.

O resgate de recidivas após tratamento radioterápico exclusivo tem mostrado resultados semelhantes aos encontrados no presente estudo ${ }^{12}$. A heterogeneidade deste grupo de pacientes e a necessidade de um tratamento individualizado dificultem a consideração de aspectos relacionados ao prognóstico, especialmente em um estudo retrospectivo.

Considerando os locais de maior risco para o desenvolvimento das recidivas, a radioterapia pósoperatória pode seguir os mesmos princípios anatômicos do esvaziamento seletivo na definição dos campos e dose de irradiação, especialmente após a realização de esvaziamento radical. O raciocínio inverso, ou seja, a realização de esvaziamento seletivo após o tratamento radioterápico do pescoço também pode ser considerado em ensaios clínicos.

\begin{abstract}
Background: To evaluate recurrence site in the neck of patients with squamous cell carcinoma of upper aerodigestive tract after neck dissection, as well as the results of salvage treatment. Method: Of 943 patients submitted to neck dissection, 95 were selected with diagnosis of neck recurrence as the first sign of relapse of disease. The location of neck disease (side and lymphatic level) and the control of disease after salvage treatment were evaluated. Results: Ipsilateral recurrences occured in level II in $57 \%$ of patients. Salvage treatment was accomplished in $51 \%$ of ipsilateral and in $75 \%$ of contralateral recurrences. Control of disease after 12 months of salvage treatment was 31\%, being $25 \%$ in ipsilateral and $37 \%$ in contralateral neck recurrences. Conclusion: Neck recurrence occur predominantly in level II. Relapse in level I is frequent only in oral cavity tumors, relapse in level $V$ is rare. Neck recurrence has poor outcome even among patients submitted to salvage treatment with curative intention.
\end{abstract}

Key words: Carcinoma, squamous cell; Neoplasm metastasis; Lymph nodes, neck dissection.

\section{REFERÊNCIAS}

1. Leemans CR, Tiwari R, Nauta JJ, et al. - Regional lymph node involvement and its significance in the development of distant metastases in head and neck carcinoma. Cancer, 1993, 71(2): 452-456.

2. Leemans CR, Tiwari R, Nauta JJ, et al. - Recurrence at the primary site in head and neck cancer and the significance of neck lymph node metastases as a prognostic factor. Cancer, 1994, 73(1): 187-190.

3. Khafif RA, Gelbfish GA, Attie JN. Thirty-year experience with 457 radical neck dissections in cancer of the mouth, pharynx, and larynx. Am J Surg, 1989, 158(4): 303-307.

4. Grandi C, Mingardo M, Guzzo M, et al. - Salvage surgery of cervical recurrences after neck dissection or radiotherapy. Head Neck, 1993, 15(4): 292-295.
5. Ambrosch P, Kron M, Pradier O, et al. - Efficacy of selective neck dissection: a review of 503 cases of elective and therapeutic treatment of the neck in squamous cell carcinoma of the upper aerodigestive tract. Otolaryngol Head Neck Surg, 2001, 124(2): 180-187.

6. Smeele LE, Leemans CR, Langendijk JA, et al. - Positive surgical margins in neck dissection specimens in patients with head and neck squamous cell carcinoma and the effect of radiotherapy. Head Neck, 2000, 22(6): 559-563.

7. Klimek T, Glanz H, Dreyer T. Histomorphological characteristics of non-metastatic lymph nodes in patients with head and neck cancer according to their site in the neck. Acta Otolaryngol, 1996, 116(2): 336340 .

8. Krol BJ, Righi PD, Paydarfar JA, et al. - Factors related to outcome of salvage therapy for isolated cervi- 
cal recurrence of squamous cell carcinoma in the previously treated neck: a multi-institutional study. Otolaryngol Head Neck Surg, 2000, 123(4): 368-376.

9. Ramanujan S, Koenig GC, Padera TP, et al. - Local imbalance of proangiogenic and antiangiogenic factors: A potential mechanism of focal necrosis and dormancy in tumors. Cancer Res, 2000, 60(5): 1442-1448.

10. Camphausen K, Moses MA, Beecken WD, et al. Radiation therapy to a primary tumor accelerates metastatic growth in mice. Cancer Res, 2001, 61(5):22072211.

11. Maniwa Y, Okada M, Ishii N, et al. - Vascular endothelial growth factor increased by pulmonary surgery accelerates the growth of micrometastases in metastatic lung cancer. Chest, 1998, 114(6): 1668-1675.
12. Mabanta SR, Mendenhall WM, Stringer SP, et al. Salvage treatment for neck recurrence after irradiation alone for head and neck squamous cell carcinoma with clinically positive neck nodes. Head Neck, 1999, 21(7): 591-594.

Endereço para correspondência:

Prof. Abrão Rapoport

Praça Amadeu Amaral, 47 - cj. 82

01327-010 - São Paulo - SP

E-mail: cpgcp.hosphel@attglobal.net 